\title{
Numerical studies on damage of carbon/epoxy composites exposed to lightning strike
}

\author{
Akhileshwar Pandey ${ }^{1}$, Ashutosh K. Upadhyay ${ }^{1}$, K.K. Shukla ${ }^{1}$ \\ ${ }^{1}$ Applied Mechanics Department, Motilal Nehru National Institute of Technology Allahabad, Prayagraj, INDIA \\ "Corresponding Author: e-mail: ashutosh@mnnit.ac.in
}

\begin{abstract}
Lighter carbon fiber/epoxy composites are replacing metals in wind turbines blades, aircraft structures, marine structures, automotive skins \& other applications. Lightning strike damage is a real threat to these materials during service life. Along with experimental studies, their damage predictions by numerical methods are being attempted by various researchers. The numerical simulation of this damage by coupled thermal-electric (transient) analysis and thermal transient analysis is presented in this article. In this study, damage predictions based on thermal profiles are carried out, and suitable validations with earlier published work are discussed.
\end{abstract}

Keywords: Lightning strike, Temperature-dependent material properties, Composite laminates, Ablation, Carbon fiber

DOI: http://dx.doi.org/10.4314/ijest.v13i1.17S

Cite this article as:

Pandey A., Upadhyay A.K., Shukla K.K. 2021. Numerical studies on damage of carbon/epoxy composites exposed to lightning strike. International Journal of Engineering, Science and Technology, Vol. 13, No. 1, pp. 112-118. doi: 10.4314/ijest.v13i1.17S

Received: December 1, 2019; Accepted: February 5, 2021; Final acceptance in revised form: March 31, 2021

This paper was earlier presented at the International Conference on Energy, Environment \& Material Sciences (ICE2M), 1-3 December 2019 and substantially improved for this Special Issue. Guest Editor: Dr. Sri Niwas Singh, Professor (HAG), Department of Electrical Engineering, Indian Institute of Technology Kanpur, 208016 (U.P.) India, former Vice-Chancellor, Madan Mohan Malviya University of Technology Gorakhpur (April 2017 to July 2020).

\section{Introduction}

Lightweight composite materials are preferred materials than metals for wind turbines blades, aircraft structures, and automotive skins. Being a good conductor of electricity, metals generally, discharge lightning very quickly so, the damage is minimal. Composite materials like CFRP, GFRP, Aramid fibers are prone to damages caused by lightning strike. Lightning may cause ablation of the surface of the structure, delaminations of composite parts, embrittlement of matrix, fiber breakage, dielectric punctures, and also sparking near joints, vaporization of electrical wiring. Composite structures can be protected by covering it with metal meshes of aluminum, copper, nickel or phosphor bronze. But, it will again increase the weight, so the benefit of using composite is hampered. To address these problem better solutions in the form of metallic coatings, metal nanowires, nanocomposites, CNT and graphene are being proposed by researchers (Feraboli et al, 2009 \& Gou et al, 2010). Current research interest lies in the prediction of damage by numerical simulations, experimental studies of damage morphology and enhancement of the electrical conductivity of composites. In this study, prediction of damage induced by lightning strike on CFRP plate is attempted. 


\section{Previous Work}

The response of composites subjected to a Lightning strike is essentially a multiphysics problem, which involves, joule heating, thermal ablation, effects of acoustic and magnetic pressure. When lightning arc strikes a composite structure, the high-velocity electric charge particles within the lightning arc channel impacts the structure and heats the material surface. The material absorbs energy from the lightning arc channel and experiences a rapid temperature rise. Under elevated temperature, fiber breakage occurs, polymer matrix gets decomposed and which further results in the diffusion of pyrolysis gas and the fluctuations of material properties.

The heat conduction is governed by the energy balance equation. To account for the electric-thermal coupling effects (if the composite material is electrically conductive, such as CFRP composites), the energy balance equation is written as:

$$
\rho C_{p} \frac{\partial T}{\partial t}=\nabla .(k \nabla t)+Q_{j}
$$

Where $\rho, \mathrm{C}_{\mathrm{p}}, \mathrm{k}$ are the instant density, specific heat, and directional thermal conductivity of the composite material, all are temperature-dependent; $\mathrm{Q}_{\mathrm{J}}$ is internal Joule heating generation. From the electric charge conservation equation:

$$
Q_{J}=J E
$$

Where $\mathrm{J}$ is the electric current density tensor and $\mathrm{E}$ is the electric field tensor. Meanwhile, the conduction of electric current is governed by Ohm's law:

$$
J=\sigma E
$$

Equations (1)-(3) have been used to formulate the thermoelectric coupling in the existing lightning strike simulation studies (Abdelal \& Murphy, 2014, Ogasawara et al, 2010,Muñoz et al, 2014, Wang \& Zhupanska, 2016, Yin et al, 2017, Wang et al, 2014, Liu et al, 2015). The coupled thermoelectric problems can be numerically solved in popular FEA solvers like ANSYS, COMSOL, and ABAQUS with material properties, geometry, and current of lightning strike as input. As of now, these solvers are not capable enough to consider heat loss due to the pyrolysis of the polymer matrix. Special arrangements like subroutines or user programs are required to incorporate pyrolysis of the polymer matrix.

When FRPs are exposed to the high energy of lightning strikes, thermal ablation occurs due to the phase transition of material. Thermal ablation damage is more due to component C, (see Fig.1) than components A or D (Kovach \&Erickson, 2013). The ablation of this type is complex and needs better understanding. For CFRP, oxidation, nitridation, and sublimation reactions along with resin decomposition takes place. Internal joule heating inside the composite structure also leads to additional mass loss (Negarestani et al, 2010, Feih \& Mouritz, 2012, Ogasawara et al, 2010). Thermal ablation modeling can be done in FE software like ABAQUS, ANSYS, and COMSOL. Further experimental validations are required for these numerical simulations. In this work, a numerical study of Joule heating and thermal ablation on carbon fiber/epoxy plate (CFRP) is carried out.

\section{Problem description and modeling}

The thermal boundary condition is applied on top and side surfaces which specify that the emissivity is 0.9 and ambient temperature is $298^{\circ} \mathrm{K}$ (refer Fig. 2). The electrical potential on the bottom and side surfaces of the composite laminate is grounded (zero volts). The material properties of epoxy composites change drastically during a lightning strike. The temperaturedependent material properties of CFRP, are given in Table I, where T denotes temperature, $\rho$ denotes density, Cp denotes specific heat, $\mathrm{K}_{\mathrm{xx}}, \mathrm{K}_{\mathrm{yy}}, \mathrm{K}_{\mathrm{zz}}$ denote thermal conductivity in the respective direction and $\sigma_{\mathrm{xx}}, \sigma_{\mathrm{yy}}, \sigma_{\mathrm{zz}}$ denote electrical conductivity in the respective directions.

Lightning waveforms and levels are significantly varied in nature, so a standardized lightning waveform is used for testing in the lab. SAE ARP 5412/EUROCAE ED-84 standards have defined these test waveforms, and one sample same is shown in Fig. 1. In this work, 4/10 waveform as per SAE ARP 5412 standard (ARP 5412, 1999) have been followed. The double exponential current waveform for component A, as suggested by Wang (Wang et al, 2017), is given in (4). A sample of the current waveform used in this study is shown in Fig. 4. Electric current is applied to the sample in the through-thickness direction and at the center of the sample for $60 \mu \mathrm{s}$.

$$
I=1.5 \times I_{\text {peak }} \times\left(e^{-7300 o t}-e^{-63000 o t}\right)
$$


The CFRP plate is modeled in ANSYS platform. All simulations were run on HP Z8 G4 workstation with 12 cores and $48 \mathrm{~GB}$ ram.

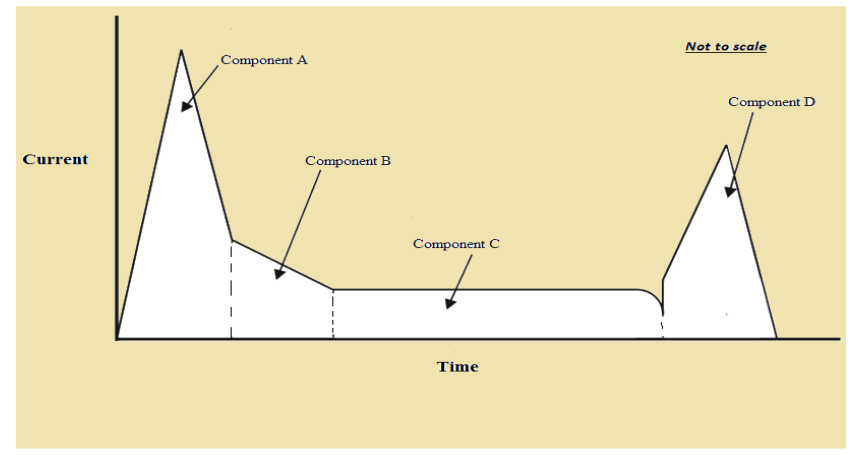

Fig. 1. SAE ARP 5412 test waveform

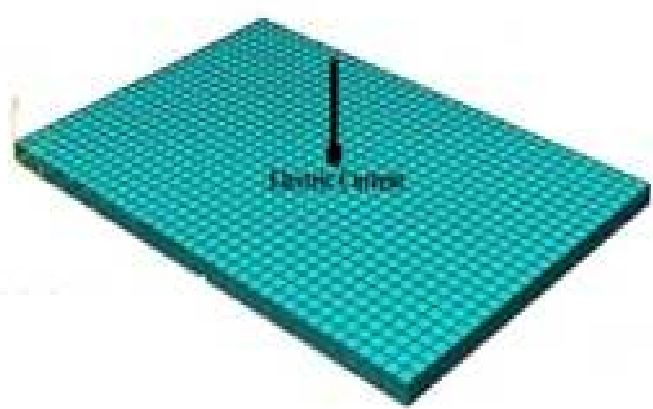

Fig. 2.Model of CFRP Plate

Table 1.Temperature dependent properties of CFRP (Wang, 2016]

\begin{tabular}{|c|c|c|c|c|c|c|c|}
\hline $\mathrm{T}\left({ }^{0} \mathrm{C}\right)$ & $\rho\left(\mathrm{kg} / \mathrm{m}^{3}\right)$ & $C_{p}(\mathrm{~J} / \mathrm{kg} K)$ & $K_{x x}(W / \mathrm{mK})$ & $\begin{array}{c}K_{y y} K_{z z}(W / \\
m K)\end{array}$ & $\begin{array}{c}\sigma_{x x}(\mathrm{~S} / \mathrm{m}) \\
\left(* 10^{-4}\right)\end{array}$ & $\begin{array}{c}\sigma_{y y}(S / m) \\
\left(* 10^{-4}\right)\end{array}$ & $\sigma_{z z}(S / m)$ \\
\hline 25 & 1520 & 1065 & 11.8 & 0.61 & 2.93 & 0.0778 & $7.94 \mathrm{E}-04$ \\
\hline 300 & 1520 & 2100 & 11.8 & 0.61 & 2.93 & 0.0778 & $7.94 \mathrm{E}-04$ \\
\hline 400 & 1520 & 2100 & 2.61 & 0.18 & 2.93 & 0.0778 & 7.94 \\
\hline 500 & 1100 & 2100 & 1.74 & 0.1 & 2.93 & 2 & $2.0 \mathrm{E}+03$ \\
\hline 600 & 1100 & 1700 & 1.74 & 0.1 & 2.93 & 2 & $2.00 \mathrm{E}+03$ \\
\hline 1000 & 1100 & 1900 & 1.74 & 0.1 & 2.93 & 2 & $2.00 \mathrm{E}+03$ \\
\hline 3316 & 1100 & 2509 & 1.38 & 0.1 & 2.93 & 2 & $2.00 \mathrm{E}+04$ \\
\hline
\end{tabular}

\section{Results and discussions}

\subsection{Joule Heating Numerical Analysis}

Three-dimensional finite element (FE) model of carbon fiber/epoxy composite of 32 ply and stacking sequence $[45 / 0 /-45 / 90]_{4 \mathrm{~s}}$ of dimension $150 \mathrm{~mm} \times 100 \mathrm{~mm} \times 4.7 \mathrm{~mm}$ is modeled in this simulation. Layup angles are achieved by changing elemental local coordinates through APDL subroutines. Coupled thermal-electrical FE element SOLID69 (8 noded, 3D) is used in this analysis. A total of 19200 elements were used with suitable mesh refinement of the model. The coupled thermo-electric transient analysis was carried out with suitable adjustments for better convergence of simulations. A current load of $40 \mathrm{kA}$, confirming to SAE-ARP5412 standard (only component A), was applied for 60 microseconds and the loading was done through 15 sub steps. Boundary conditions were assumed uniform throughout the loading of electrical current. Useless to reiterate that, material properties are temperature-dependent and the same are given in Table I. 
Fig. 3 shows the prediction of damage of the top layer from this study and experimental damage of sample (bulk) under the same conditions by Ogasawara et al. [4]. In this numerical simulation, the damage is predicted with iso-thermal contours which are essentially contours of similar temperature, this is endorsed by several researchers (Abdelal \& Murphy, 2014, Ogasawara et al, 2010,Muñoz et al, 2014, Wang \& Zhupanska, 2016, Yin et al, 2017, Wang et al, 2014, Liu et al, 2015). It is apparent that the damage is aligned in $45^{\circ}$ fiber orientation (top layer) and of the fan shape. So, it can be said, that isotherm contours are related to lightning strike damage. Damage area shown in experimental work is not matching to predicted damage by this numerical study is obvious, because only joule heating effects are considered in this study other effects such as magnetic pressure, acoustic and ablation are not considered at this point of time. But certainly, it is found that numerical simulations based on joule heating equations are capable to capture damage due to lightning strikes. A numerical model that comprises all loadings viz. current, heat, acoustic and magnetic pressure is highly pursuit and the same would be capable of predicting lightning damage on composites. But, to the best of the authors' knowledge, no such study has been reported yet.

\subsection{Thermal Ablation Numerical Analysis}

Transient thermal analysis is carried out for modeling of thermal ablation. Ablation damage is captured by progressive element deletion at pre-decided ablation temperature, unlike the previous one where damage was captured by isotherm contours. Thermal decomposition of epoxy starts when the temperature reaches $260^{\circ} \mathrm{C}$ and the sublimation of carbon fiber happens when the temperature is $3316^{\circ} \mathrm{C}$. During analysis, if the mean temperature of an element is more than $260^{\circ} \mathrm{C}$, then that element is deleted. This element deletion is carried out by suitable APDL codes, which were developed by authors. Furthermore, the lightning strike channel (assumed cylindrical in this study) expands i.e. its radius keeps on increasing during lightning. So, this was also incorporated in this study by in-house developed APDL scripts. The heat generated by an incident lightning current is given by Wang, 2016 and the same is given in equation 5. From this equation, heat flux is obtained as a function of channel radius and time.

$$
\begin{aligned}
& \mathrm{Q}(\mathrm{r}, \mathrm{t})=-\frac{\ln (0.1)}{0.55^{2}} \frac{10}{1-\mathrm{e}^{A}} \frac{I(t)}{\pi R^{2}(t)} \mathrm{e}^{\mathrm{B}}, \mathrm{r} \leq \mathrm{R}(\mathrm{t}) \\
& A=\frac{\ln (0.1)}{0.55^{2}} R^{2}(t) \quad ; \quad B=\frac{\ln (0.1)}{(0.55 R(t))^{2}} r^{2}
\end{aligned}
$$
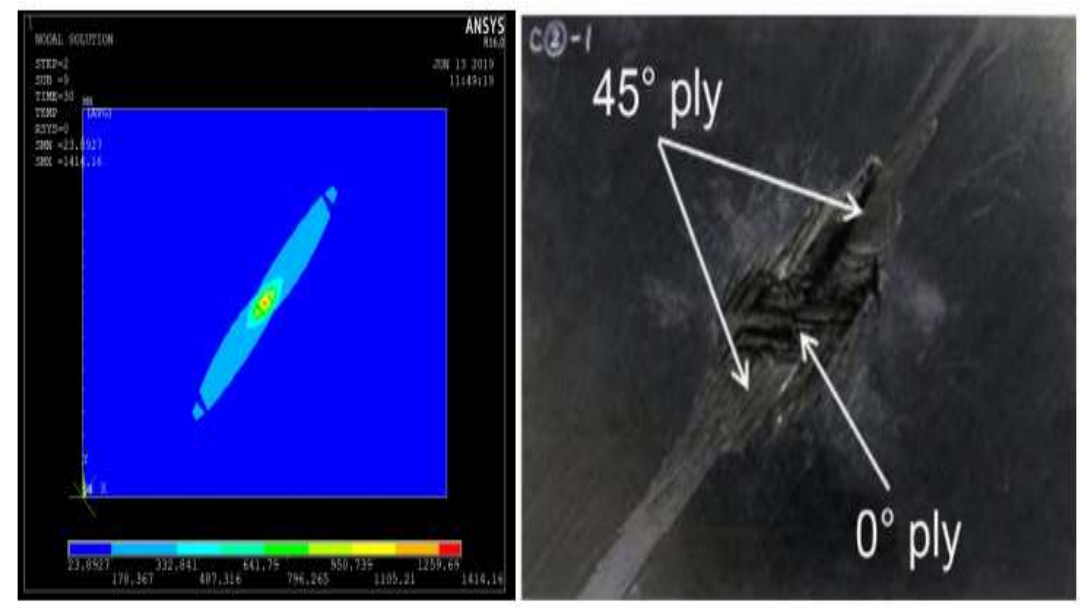

Fig. 3.Damage prediction of the top layer by this study and reported experimental damage by Ogasawara et al., 2010 


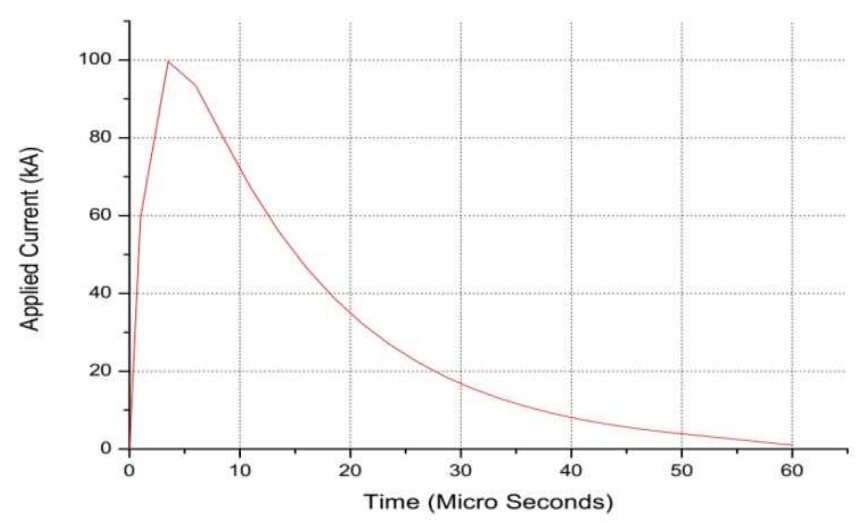

Fig. 4.Component A of $100 \mathrm{kA}$ electric current waveform

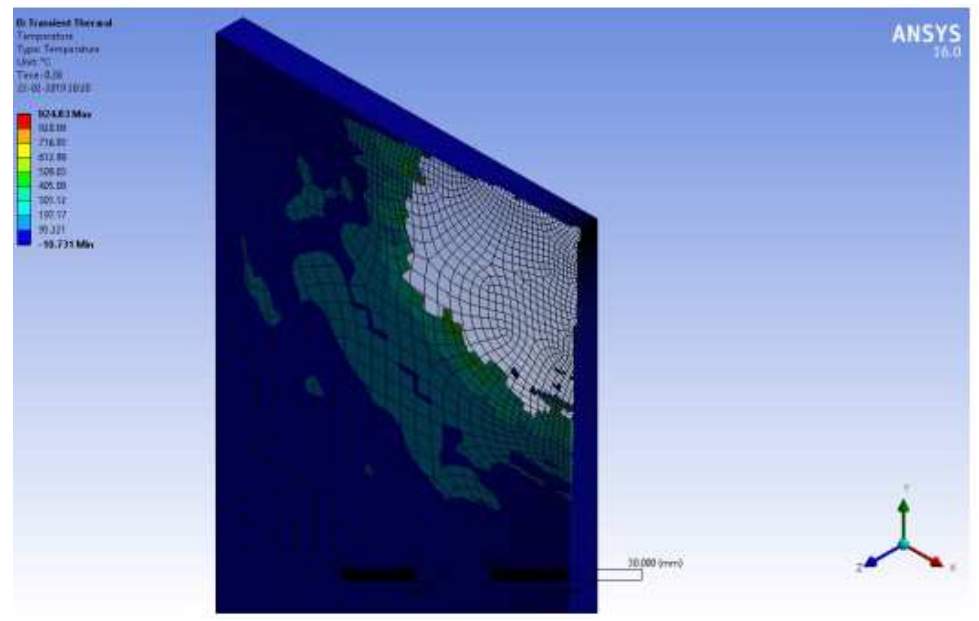

Fig. 5.Thermal ablation damage of quarter plate of CFRP

Three-dimensional finite element (FE) model of a quarter of 8 ply and stacking sequence [45/0/- 45/90]s of dimension150 mm $\times 100 \mathrm{~mm} \times 3.8 \mathrm{~mm}$ is modeled in this simulation. This model is prepared in the ACP Pre module of ANSYS workbench. The temperature-dependent material properties of carbon fiber/epoxy composite were taken from Table I. Layup angles were achieved by changing elemental local coordinates through the APDL subroutines. 8 nodes, 3D solid layered thermal element SOLID278 is used for this transient thermal analysis. In this model, a total of 27672 elements were used with suitable mesh refinement at the point of load application. A heat flux, corresponding to 100kA, confirming to SAE-ARP-5412 standard (ref fig. 4 \& equation 5), was applied for 60 microseconds followed by a steady-state cooling of 0.26 seconds. Boundary conditions were assumed uniform throughout the loading but it needs to be updated after each load step.

From Fig. 5, the deleted elements can be very easily identified. This deleted element area is assumed as a thermal ablation damage area. It is also shown that ablation damage is in fiber direction and through-thickness damage is also observed. In ANSYS code, the temperature is calculated at nodal values (d.o.f.), for element, the averages of these nodal values are taken. Nodes that have a temperature higher than $260^{\circ} \mathrm{C}$ are present in results. This happened because it is a plot of nodal values and element deletion is done as per average element temperature. Zones of charred state of epoxy may be thought of as area between deleted elements (grey) and unaffected zones (blue) i.e. area shown by green, light green or bluish-green. From these discussions, it may be concluded that the element deletion pertaining to thermal decomposition of epoxy, is related to thermal ablation damage. This methodology also captures the damage in the through-thickness direction. 


\section{Conclusions}

Preliminary results of numerical studies show that the lightning strike damage of composites can be predicted by suitable numerical model. Isotherm contours and element deletion methodology can be used for damage predictions. Lightning strike is a highly dynamic \& complex phenomenon. Its damage predictions require proper modeling of electrical, thermal, mechanical, chemical, and acoustic effects. Detailed mechanisms of damages occurred due to lightning strikes on composite structures and its numerical modeling is yet to be established.

\begin{tabular}{ll}
\multicolumn{2}{l}{ Nomenclature } \\
$\rho$ & density \\
$\mathrm{C}_{\mathrm{p}}$ & specific heat \\
$\mathrm{k}$ & thermal conductivity \\
$\mathrm{J}$ & electric current density tensor \\
$\mathrm{E}$ & electric field tensor \\
$\mathrm{Q}_{\mathrm{J}}$ & internal joule heat \\
$\mathrm{I}$ & current \\
$\mathrm{Q}$ & heat flux \\
$\mathrm{R}_{(\mathrm{r}, \mathrm{t})}$ & channel radius
\end{tabular}

\section{References}

Aircraft lightning environment and related test waveforms, aerospace recommended practice ARP 5412, SAE, 1999.

D. J. Kovach and G. J. Erickson, 2013. LSP composite substrate destructive evaluation test assessment manual, NASA, Tech. Rep.

F. Wang, N. Ding, Z. Liu, Y. Ji, and Z. Yue, 2014. Ablation damage characteristic and residual strength prediction of carbon fiber/epoxy composite suffered from lightning strike," Composite Structures, vol. 117, pp. 222 - 233. DOI: https://doi.org/10.1016/j.compstruct.2014.06.029

G. Abdelal and A. Murphy, 2014. Nonlinear numerical modeling of lightning strike effect on composite panels with temperature dependent material properties, Composite Structures, vol. $109, \quad$ pp. 268 - $278 . \quad$ DOI: https://doi.org/10.1016/j.compstruct.2013.11.007

J. Gou, Y. Tang, F. Liang, Z. Zhao, D. Firsich, and J. Fielding, 2010. Carbon nanofiber paper for lightning strike protection of composite materials, Composites Part B: Engineering, vol. 41, no. 2, pp. 192-198. DOI: https://doi.org/10.1016/j.compositesb.2009.06.009

J. Yin, F. Chang, S. Li, X. Yao, J. Sun, and Y. Xiao, 2017. Lightning strike ablation damage influence factors analysis of carbon fiber/epoxy composite based on coupled electrical-thermal simulation, Applied Composite Materials, vol. 24, no. 5, pp. 1089_ 1106. DOI: https://doi.org/10.1007/s10443-016-9577-1

P. Feraboli and M. Miller, 2009. Damage resistance and tolerance of carbon/epoxy composite coupons subjected to simulated lightning strike, Composites Part A: Applied Science and Manufacturing, vol. 40, no. 6-7, pp. 954-967. DOI: https://doi.org/10.1016/j.compositesa.2009.04.025

R. Muñoz, S. Delgado, C. González, B. López-Romano, D.-Y. Wang, and J. LLorca, 2014. Modeling lightning impact thermomechanical damage on composite materials, Applied Composite Materials, vol. 21, no. 1, pp. 149-164. DOI: https://doi.org/10.1007/s10443-013-9377-9

R. Negarestani, L. Li, H. Sezer, D. Whitehead, and J. Methven, 2010. Nanosecond pulsed laser cutting of cfrp composites with mixed reactive and inert gases, The International Journal of Advanced Manufacturing Technology, vol. 49, no. 5-8, pp. 553566. DOI: https://doi.org/10.1007/s00170-009-2431-y

S. Feih and A. Mouritz,2012.Tensile properties of carbon fibres and carbon fibre-polymer composites in fire, Composites Part A: Applied Science and Manufacturing, vol. 43, no. 5, pp. 765-772. DOI: https://doi.org/10.1016/j.compositesa.2011.06.016

T. Ogasawara, Y. Hirano, and A. Yoshimura, 2010. Coupled thermal electrical analysis for carbon fiber/epoxy composites exposed to simulated lightning current, Composites Part A: Applied Science and Manufacturing, vol. 41, no. 8, pp. 973 - 981. DOI: https://doi.org/10.1016/j.compositesa.2010.04.001

Y. Wang, 2016. Modeling of lightning-induced thermal ablation damage in anisotropic composite materials and its application to wind turbine blades, Ph.D. dissertation, University of Iowa. DOI: 10.17077/etd.c1auwcsz

Y. Wang, N. Shen, G. K. Befekadu, and C. L. Pasiliao,2017.Modeling pulsed laser ablation of aluminum with finite element analysis considering material moving front, International Journal of Heat and Mass Transfer, vol. 113, pp. 1246-1253. https://doi.org/10.1016/j.ijheatmasstransfer.2017.06.056

Y. Wang and O. I. Zhupanska, 2016, Thermal ablation in fiber-reinforced composite laminates subjected to continuing lightning current, in 57th AIAA/ASCE/AHS/ASC Structures, Structural Dynamics, and Materials Conference, p. 0986. DOI: https://doi.org/10.2514/6.2016-0986 
Z. Liu, Z. Yue, F. Wang, and Y. Ji, 2015. Combining analysis of coupled electrical-thermal and blow-off impulse effects on composite laminate induced by lightning strike, Applied Composite Materials, vol. 22, no. 2, pp. 189-207. DOI: https://doi.org/10.1007/s10443-014-9401-8

\section{Biographical notes}

Akhileshwar Pandey received M. Tech. from MNNIT ALLAHABAD, India in 2007. He is a Assistant Professor in the Department of Mechanical Engineering, Govt Engineering College Bharatpur, India. Presently he is pursuing PhD from MNNIT ALLAHABAD under supervision of Dr. Ashutosh K Upadhyay \& Prof K.K. Shukla. His research interests include lighting strike on composites, and sandwich structures.

Dr. Ashutosh K Upadhyay is Associate Professor in the Department of Applied Mechanics, MNNIT Allahabad, U.P., India, has more than 12 years of experience in teaching and research. Composite Structures, Plates and Shells, Impact Mechanics (Low Velocity and Ballistic), Vehicle Crashworthiness and Energy absorbers (Thin-walled tubes, Sandwich constructions), Lightning Strike on Composites,

Prof K. K. Shukla, Department of Applied Mechanics, MNNIT Allahabad, U.P., India, has more than 32 years of experience in teaching and research. He specializes in areas such as Composite Plates and Shells, Smart Structures, Retrofitting \& Strengthening of RCC Structures, Computational Mechanics, Stability \& Dynamics of Structures, Multi-scale Composite. He has authored the book "An Introduction to Strength of Materials". He was a Visiting Research Fellow, Mechanical and Computer Aided Engineering Department, Feng Chia University, Taichung, Taiwan during Nov. 2002- March 2003 and June 2004. 